\author{
M. J. Holness • N. D. Smith • G. K. Greenwood • \\ M. C. Sugden
}

\title{
Interactive influences of peroxisome proliferator-activated receptor $\alpha$ activation and glucocorticoids on pancreatic beta cell compensation in insulin resistance induced by dietary saturated fat in the rat
}

Received: 2 February 2005 / Accepted: 19 May 2005 / Published online: 19 August 2005

(C) Springer-Verlag 2005

\begin{abstract}
Aims/hypothesis: We sought to elucidate whether excess glucocorticoids and increased dietary lipids act synergistically to impair glucose tolerance and, if so, whether activation of peroxisome proliferator-activated receptor $\alpha(\operatorname{PPAR} \alpha)$ has an adverse or beneficial effect on glucose tolerance. Methods: Dexamethasone $(100 \mu \mathrm{g}$ $\mathrm{kg}^{-1}$ body weight day ${ }^{-1}$; 5 days) was administered to insulin-resistant rats fed a high-saturated-fat (HF) diet for 4 weeks. The PPAR $\alpha$ agonist WY14643 was administered (50 mg kg-1 body weight intraperitoneally) $24 \mathrm{~h}$ before sampling. Glucose-stimulated insulin secretion (GSIS) was assessed in vivo after an acute glucose bolus injection, and in vitro using step-up and step-down islet perifusions. Results: Although neither PPAR $\alpha$ activation nor dexamethasone alone affected fasting glycaemia in the HF group, dexamethasone in combination with $\operatorname{PPAR} \alpha$ activation elicited marked postabsorptive hyperglycaemia. Dexamethasone treatment of HF rats had little effect on GSIS after an acute glucose challenge in vivo, but induced glucose intolerance. PPAR $\alpha$ activation augmented GSIS in dexamethasone-treated HF rats in vivo, restoring glucose tolerance. Contrasting with data obtained in vivo, greatly enhanced peak rates of GSIS were observed ex vivo in perifusions of islets from dexamethasone-treated HF rats compared with those from untreated HF rats, an effect attenuated by antecedent PPAR $\alpha$ activation. Conclusions/ interpretation: The study demonstrates that glucocorticoid excess precipitates the development of glucose intolerance in rats maintained on a high-saturated-fat diet. It does this by interrupting the negative feedback loop between insulin sensitivity and secretion in vivo, such that further enhance-
\end{abstract}

\footnotetext{
M. J. Holness · N. D. Smith · G. K. Greenwood

M. C. Sugden $(\triangle)$

Centre for Diabetes and Metabolic Medicine,

Institute of Cell and Molecular Science, Barts and the London,

Queen Mary's School of Medicine and Dentistry,

University of London,

London, UK

e-mail: m.c.sugden@qmul.ac.uk

Tel.: +44-20-78822355

Fax: +44-20-78822186
}

ment of compensatory insulin secretion is not possible. $\operatorname{PPAR} \alpha$ activation restores the coupling between insulin secretion and action.

Keywords Compensatory insulin secretion

Glucocorticoids · Glucose-stimulated insulin secretion ·

Insulin resistance - Islet perifusions $\operatorname{PPAR} \alpha$.

Saturated fat

Abbreviations AIR: acute insulin response - DEX: dexamethasone $\cdot \Delta \mathrm{G}$ : incremental blood glucose values integrated over the 30-min period after intravenous injection of glucose $\cdot \Delta \mathrm{I}$ : incremental plasma insulin values integrated over the 30-min period after intravenous injection of glucose - GSIS: glucose-stimulated insulin secretion $\cdot$ HF: high fat $k$ : rate of glucose disappearance PPAR: peroxisome proliferator-activated receptor - WY: WY14643

\section{Introduction}

The liver is a major target tissue for the glucocorticoids, which increase hepatic glucose production by stimulating gluconeogenesis (reviewed in [1]). This action is important for maintaining glycaemia in starvation, where increased fatty acid oxidation spares pyruvate for gluconeogenesis via inhibition of the pyruvate dehydrogenase complex, and provides ATP and cofactors for gluconeogenesis. However, glucocorticoids at excessive levels can induce insulin resistance and precipitate glucose intolerance [1-3]. Lowering of circulating fatty acid concentrations reverses insulin resistance in human subjects treated with glucocorticoids [4]. Thus, either lipid oxidation and/or altered lipid signalling is involved in the mechanism by which glucocorticoid excess induces whole-body insulin resistance. The PPAR (peroxisome proliferator-activated receptor) subtypes $(\alpha, \gamma, \delta)$ are lipid-responsive transcription factors that regulate lipid storage and oxidation. PPAR $\alpha$ is highly expressed in liver [5], where its activation promotes hepatic 
fatty acid oxidation [6, 7]. Glucocorticoids induce PPAR $\alpha$ expression in cultured hepatocytes and intact liver in rodents [8]. Importantly, PPAR $\alpha$ is required for hepatic insulin resistance to be induced in response to the administration of the synthetic glucocorticoid dexamethasone [9]. Increased dietary saturated fat can also elicit the development of insulin resistance [10-12] (reviewed in [13, 14]). However, contrasting with the facilitatory role of PPAR $\alpha$ in the induction of hepatic insulin resistance in response to glucocorticoids, PPAR $\alpha$ activation improves insulin sensitivity in the high dietary fat model of insulin resistance [15, 16]. The differences in the influence of PPAR $\alpha$ activation on insulin resistance induced by glucocorticoids and that induced by high-saturated-fat feeding may reflect the underlying mechanisms invoking insulin resistance in these two states, namely a more hepatocentric action in glucocorticoid-induced insulin resistance, contrasting with a wider influence of high-fat feeding to induce tissue lipid accumulation with resultant dysregulation of insulin signalling. Importantly, there is increasing evidence that long-term lipid sensing by the pancreatic beta cell could be coordinated through the expression and/or activity of PPAR $\alpha[17,18]$ (reviewed in $[19,20]$ ). We have recently established that activation of PPAR $\alpha$ can oppose insulin hypersecretion elicited by high-fat feeding via stable long-term effects exerted on islet function [15].

In the present study, we therefore sought to elucidate whether excess glucocorticoids and increased dietary lipid act synergistically to impair glucose tolerance and, if so, whether PPAR $\alpha$ activation has an adverse or beneficial effect on glucose tolerance. We analysed our data in relation to effects of these manipulations on glucose-stimulated insulin secretion (GSIS), the induction of insulin resistance in the intact animal and direct long-term adaptations of islet function. By extending our studies to islet perifusions, we exclude the influence of circulating factors that may signal changes in insulin action in tissues other than the islet.

\section{Materials and methods}

\section{Materials}

General Laboratory reagents were from Roche Diagnostics (Lewes, UK) or from Sigma (Poole, UK). Kits for determination of insulin (ELISA, rat insulin as standard), glucose (glucose oxidase) and leptin (ELISA, rat leptin as standard) were from Mercodia (Uppsala, Sweden), Roche Diagnostics and Metachem Diagnostics (Northampton, UK). Dexamethasone (sodium phosphate) was obtained from David Bull Laboratories (Warwick, UK). Mini-osmotic pumps were purchased from Charles River (Margate, UK). WY14643 (pirinixic acid) was purchased from Sigma.

\section{Animals}

All studies were conducted in adherence to the regulations of the United Kingdom Animal Scientific Procedures Act
(1986). Female Wistar rats (200-250 g) were purchased from Charles River Laboratories. Rats were subjected to a standard light (08:00-20:00 h)-dark (20:00-08:00 h) cycle in a temperature-controlled room $\left(21 \pm 2^{\circ} \mathrm{C}\right)$. The rats were housed in individual cages and were given free access to water and to a semi-synthetic diet high in saturated fat for 4 weeks (for details see [11, 12]) (HF group). Dexamethasone $\left(100 \mu \mathrm{g} \mathrm{kg}^{-1}\right.$ body weight day ${ }^{-1} ; 5$ days) was administered to HF rats via indwelling osmotic pumps [21] for the last 5 days of the 4-week period of high-fat feeding (HF-DEX group). An initial priming dose $(0.1 \mathrm{mg})$ of dexamethasone was given by subcutaneous injection before minipump implantation. This procedure leads to almost total suppression of endogenous corticosterone levels (results not shown). Sham operations involving incision and manipulation under anaesthesia identical to the procedure for implantation of the osmotic minipump were undertaken on a second (control) group of rats. The PPAR $\alpha$ agonist WY14643 (or vehicle) was administered as a single intraperitoneal injection ( $50 \mathrm{mg} \mathrm{kg}^{-1}$ body weight), and rats were sampled after $24 \mathrm{~h}[15,22]$ (HF-WY and HFDEX-WY groups). We used acute $(24 \mathrm{~h})$ exposure to WY14643, rather than longer term repeated administration over several days, since we have previously demonstrated that activation of PPAR $\alpha$ by a single bolus dose of WY14643 opposes insulin hypersecretion elicited by high-fat feeding [15], and therefore the present study can be compared directly with our earlier studies.

\section{Intravenous glucose tolerance tests}

Glucose was administered as an intravenous bolus $(0.5 \mathrm{~g}$ glucose $\mathrm{kg}^{-1}$ body weight; $150 \mu \mathrm{l}$ per $100 \mathrm{~g}$ body weight) to conscious, unrestrained rats in the postabsorptive state $6 \mathrm{~h}$ after food withdrawal $[12,23]$. Glucose was injected via a chronic indwelling jugular cannula and blood samples $(100 \mu \mathrm{l})$ were withdrawn at intervals from the indwelling cannula, which was flushed with saline after the injection of glucose to remove residual glucose. Samples of whole blood $(50 \mu \mathrm{l})$ were deproteinised with $\mathrm{ZnSO}_{4} / \mathrm{Ba}(\mathrm{OH})_{2}$ and centrifuged $(10,000 \mathrm{~g})$ at $4^{\circ} \mathrm{C}$, and the supernatant was retained for subsequent assay of blood glucose. The remaining blood sample was immediately centrifuged $(10,000 \mathrm{~g})$ at $4^{\circ} \mathrm{C}$, and plasma was stored at $-20^{\circ} \mathrm{C}$ until assayed for insulin. The acute insulin response (AIR) was calculated as the mean of suprabasal 2-min and 5-min plasma insulin values. Insulin and glucose responses during the glucose tolerance test were used for calculation of the incremental plasma insulin values integrated over the 30 -min period after the injection of glucose $(\Delta I)$ and the corresponding incremental integrated plasma glucose values $(\Delta G)$. The rate of glucose disappearance $(k)$ was calculated from the slope of the regression line obtained with log-transformed glucose values from 2 to $15 \mathrm{~min}$ after glucose administration. 
Islet isolation and perifusion

Rats were anaesthetised by injection of sodium pentobarbital $\left(60 \mathrm{mg} \mathrm{ml}^{-1}\right.$ in $0.9 \% \mathrm{NaCl} ; 1 \mathrm{ml} \mathrm{kg}^{-1}$ body weight intraperitoneally) and, once locomotor activity had ceased, pancreases were excised and islets isolated by collagenase digestion. Free islets were collected under a dissecting microscope with a $20 \mu \mathrm{l}$ pipette into HEPES-buffered Hanks' balanced salt solution containing 5\% BSA. Insulin release from freshly isolated islets was measured in a perifusion system as described $[15,24]$. In this system, 50 islets were housed in small chambers on Millicell culture plate inserts (Sigma, Poole, Dorset, UK). Islets were perifused in basal medium (Krebs-Ringer containing $20 \mathrm{mmol} \mathrm{l}^{-1}$ HEPES, pH7.4, $5 \mathrm{mg} \mathrm{ml}^{-1}$ BSA and $2 \mathrm{mmol} \mathrm{l}^{-1}$ glucose) for $60 \mathrm{~min}$ at a flow rate of $1 \mathrm{ml}$ $\min ^{-1}$ at $37^{\circ} \mathrm{C}$ prior to collection of fractions. Glucose concentrations were then modified as indicated. Fractions $(2 \mathrm{ml})$ were collected at $2-\mathrm{min}$ intervals and stored at $-20^{\circ} \mathrm{C}$ prior to assay for insulin.

\section{Statistical analysis}

Results are presented as the means \pm SEM, with the numbers of rats or islet preparations in parentheses. Statistical analysis was performed by ANOVA followed by Fisher's post hoc tests for individual comparisons or Student's $t$-test as appropriate (Statview; Abacus Concepts, Berkeley, CA, USA). A $p$ value of $<0.05$ was considered to be statistically significant.

\section{Results}

PPAR $\alpha$ activation enables dexamethasone to elicit marked postabsorptive hyperglycaemia in rats maintained on a high-fat diet $\mathrm{HF}$ rats treated with dexamethasone (HFDEX group) did not display significantly higher postabsorptive hyperglycaemia compared with the HF group (Fig. 1a). PPAR $\alpha$ activation by treatment with the PPAR $\alpha$ agonist WY14643 did not affect fasting hyperglycaemia in $\mathrm{HF}$ rats (Fig. 1b). In marked contrast, PPAR $\alpha$ activation in combination with dexamethasone treatment led to very marked postabsorptive hyperglycaemia in high-fat-fed rats (HF-DEX-WY group) (Fig. 1b). Postabsorptive glucose levels in the HF-DEX-WY group were 57\% higher than those of the HF group, $47 \%$ higher than those of the HFWY group and $41 \%$ higher than those of the HF-DEX group.

$\operatorname{PPAR} \alpha$ activation improves glucose tolerance in dexamethasone-treated high-fat-fed rats

Blood glucose concentrations at intervals after an intravenous glucose bolus are shown in Fig. 1a and b. Values of

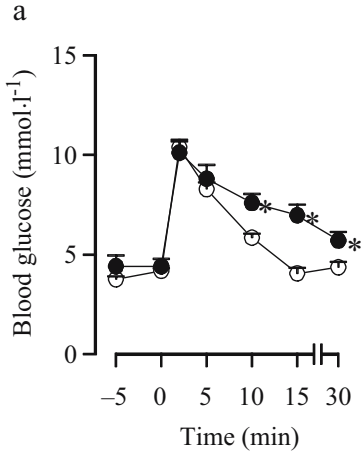

b

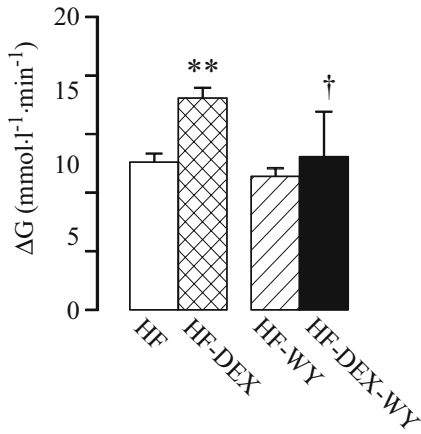

d

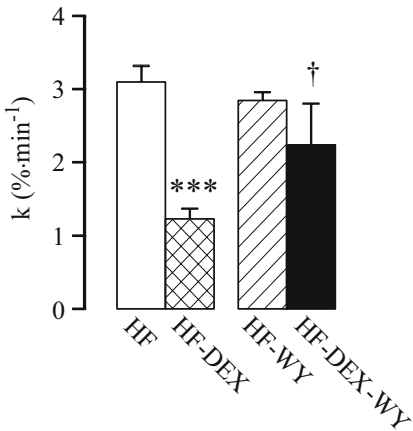

Fig. 1 Interactive effects of dexamethasone and PPAR $\alpha$ activation on parameters of glucose tolerance in high-fat-fed rats in vivo. Blood samples were withdrawn from untreated or dexamethasonetreated rats maintained on a high-saturated-fat diet (HF and HF-DEX groups) immediately before (postabsorptive state) and at intervals after an intravenous glucose bolus for measurement of blood glucose concentrations. Subgroups of HF and HF-DEX groups were administered the PPAR $\alpha$ agonist WY14643 as a single intraperitoneal injection ( $50 \mathrm{mg} \mathrm{kg}{ }^{-1}$ body weight), and rats were sampled after a further $24 \mathrm{~h}$ (HF-WY and HF-DEX-WY groups). Blood glucose concentrations before and at intervals after an intravenous glucose bolus in the HF (open symbols) and HF-DEX (closed symbols) groups (a) and in the HF-WY (open symbols) and HFDEX-WY (closed symbols) groups (b). Glucose responses during the glucose tolerance test were used for calculation of the incremental blood glucose values integrated over the 30 -min period after the injection of glucose $(\Delta \mathrm{G})$. Rates of glucose disappearance $(k)$ were calculated from the slopes of the regression lines obtained with log-transformed glucose values from 2 to $15 \mathrm{~min}$ after glucose administration and expressed as $\% \mathrm{~min}^{-1} . \Delta \mathrm{G}(\mathbf{c})$ and $k$ values (d) are shown for the HF (open bars), HF-DEX (cross-hatched bars), HF-WY (hatched bars) and HF-DEX-WY (closed bars) groups. Results are means \pm SEM for eight HF, five HF-DEX, six HF-WY and five HF-DEX-WY rats. ${ }^{*} p<0.05,{ }^{* *} p<0.01$ and ${ }^{* * *} p<0.001$ for effects of dexamethasone treatment; ${ }^{\dagger} p<0.05$ for effects of WY14643 treatment

$\Delta \mathrm{G}$ (the incremental blood glucose values integrated over the 30-min period after the injection of glucose) and $k$ (rate of glucose disappearance) after intravenous glucose challenge are shown in Fig. 1c and d respectively. Dexamethasone treatment of HF rats (HF-DEX group) resulted in a significant loss of glucose tolerance, with significantly increased blood glucose concentrations in HF-DEX rats compared with $\mathrm{HF}$ rats at 10 (by $30 \% ; p<0.05$ ), 15 (by 
$72 \% ; p<0.05$ ) and 30 (by $39 \% ; p<0.05$ ) min after the glucose bolus (Fig. 1a), together with a significantly increased $\Delta \mathrm{G}$ (by $43 \% ; p<0.01$ ) (Fig. 1c) and a significantly decreased $k$ value (by $60 \% ; p<0.001$ ) (Fig. 1d). PPAR $\alpha$ activation in vivo, elicited by the administration of WY14643, did not affect glucose tolerance in HF rats. Thus, blood glucose concentrations, $\Delta \mathrm{G}$ and $k$ values after an intravenous glucose load were similar in HF and HFWY rats (Fig. 1). In contrast, PPAR $\alpha$ activation opposed glucose intolerance elicited by dexamethasone treatment of $\mathrm{HF}$ rats, as indicated by the decline in $\Delta \mathrm{G}$ (Fig. 1c) and the increase in the $k$ value for glucose disappearance (Fig. 1d). Thus, although PPAR $\alpha$ activation in dexamethasonetreated HF rats exacerbates hyperglycaemia in the fasted state, it improves glucose tolerance after an acute glucose load.

PPAR $\alpha$ activation exaggerates postabsorptive hyperinsulinaemia induced by dexamethasone treatment of high-fat-fed rats and augments glucosestimulated insulin secretion in dexamethasone-treated high-fat-fed rats in vivo

Plasma insulin concentrations before and at intervals after an intravenous glucose bolus are shown in Fig. 2a and b. Dexamethasone treatment of $\mathrm{HF}$ rats led to increased postabsorptive insulin concentrations to values $>5$-fold higher $(p<0.001)$ than those of the HF group (Fig. 2a). $\operatorname{PPAR} \alpha$ activation did not affect postabsorptive insulin levels in HF rats, but further increased postabsorptive hyperinsulinaemia in dexamethasone-treated, high-fat-fed rats (HF-DEX-WY group) (by 35\%; $p<0.05$ ) (Fig. 2b). Insulin responses to acute intravenous glucose challenge in vivo were used for calculation of acute insulin response (AIR) values (means of suprabasal 2-min and 5-min plasma insulin values) (Fig. 2c) and total suprabasal 30min incremental areas under the curves for insulin $(\Delta \mathrm{I})$ (Fig. 2d). Dexamethasone treatment of HF rats significantly impaired the incremental increase in plasma insulin concentrations 2 and 5 min after the glucose bolus such that the AIR value was suppressed by $37 \%(p<0.05)$. Nevertheless, $\Delta \mathrm{I}$ was unaffected due to significantly higher incremental plasma insulin values at later times (10 and $15 \mathrm{~min}$ ) after glucose administration $(p<0.05)$ (Fig. 2a). $\operatorname{PPAR} \alpha$ activation significantly lowered plasma insulin concentrations 2 and 5 min after the glucose bolus in highfat-fed rats (by 38 and 34\%; $p<0.05$ in both cases) (Fig. 2b). As a consequence, significant decreases in both AIR (by $39 \% ; p<0.05$ ) and $\Delta \mathrm{I}$ (by $32 \% ; p<0.05$ ) were observed in HF-WY rats compared with HF rats (Fig. 2c,d). In marked contrast, PPAR $\alpha$ activation in combination with dexamethasone treatment dramatically increased plasma insulin concentrations after the glucose bolus (Fig. 2b), resulting in significant increases in AIR (by 1.7-fold; $p<0.001$ ) and $\Delta \mathrm{I}$ (by 1.8 -fold; $p<0.01$ ) values in HF-DEXWY rats compared with HF rats (Fig. 2).
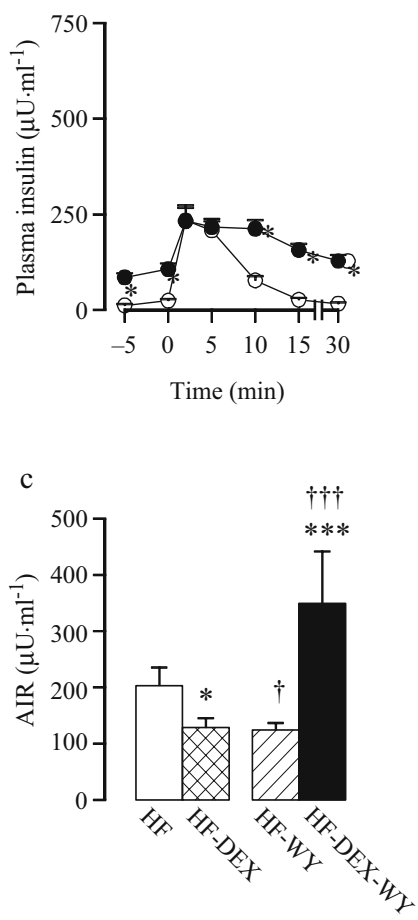

d

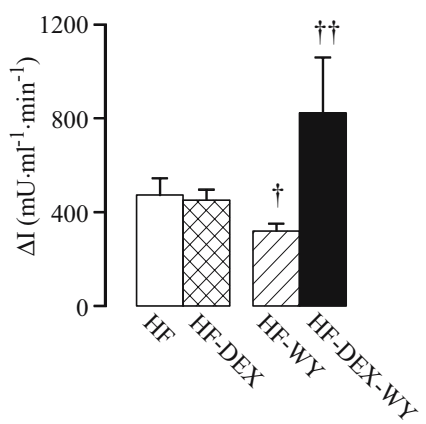

Fig. 2 Interactive effects of dexamethasone and PPAR $\alpha$ activation on basal and glucose-stimulated insulin secretion in high-fat-fed rats in vivo. Group designations and further details, see Fig. 1. Plasma insulin concentrations before and at intervals after an intravenous glucose bolus in the HF (open symbols) and HF-DEX (closed symbols) groups (a) and in the HF-WY (open symbols) and HFDEX-WY (closed symbols) groups (b). The acute insulin response (AIR) was calculated as the mean of suprabasal 2-min and 5-min plasma insulin values. Insulin responses during the glucose tolerance test were used for calculation of the incremental plasma insulin values integrated over the 30-min period after the injection of glucose $(\Delta \mathrm{I})$. AIR (c) and $\Delta \mathrm{I}$ values $(\mathbf{d})$ for the HF (open bars), HFDEX (cross-hatched bars), HF-WY (hatched bars) and HF-DEXWY (closed bars) groups are shown. Results are means \pm SEM for eight HF, five HF-DEX, six HF-WY and five HF-DEX-WY rats. $* p<0.05$ and $* * * p<0.001$ for effects of dexamethasone treatment; ${ }^{\dagger}<<0.05,{ }^{\dagger \dagger} p<0.01$, and ${ }^{\dagger \dagger} p<0.001$ for effects of WY14643

Dexamethasone treatment of high-fat-fed rats enhances GSIS in perifused islets, an effect attenuated by antecedent PPAR $\alpha$ activation

Contrasting with data obtained in vivo, greatly enhanced peak rates of GSIS were observed ex vivo in perifusions of islets from HF-DEX compared with HF rats (by 2.6-fold; $p<0.05$ ) (Fig. 3a). Furthermore, whereas PPAR $\alpha$ activation augmented GSIS in vivo in HF-DEX rats, differences in the GSIS profiles between HF and HF-DEX groups at high glucose were greatly attenuated by PPAR $\alpha$ activation (i.e. after WY14643 treatment), indicating partial reversal of the effects of dexamethasone (Fig. 3b). This implies that the direct effect of PPAR $\alpha$ activation on islet function ex vivo is dominant to that of the direct action of glucocorticoids on islet function ex vivo. To allow direct comparison of insulin secretory responses during the step-up and stepdown phases of the islet perifusions, areas under the insulin 
Fig. 3 Interactive effects of dexamethasone treatment and $\operatorname{PPAR} \alpha$ activation on glucose responsiveness of insulin secretion by perifused islets from high-fat-fed rats. Islets isolated from the four groups of rats (designations as in Fig. 1) were perifused in basal medium containing $2 \mathrm{mmol} \mathrm{l}^{-1}$ glucose for $60 \mathrm{~min}$ at a flow rate of $1 \mathrm{ml}$ $\mathrm{min}^{-1}$ at $37^{\circ} \mathrm{C}$ prior to collection of fractions. Perifusate glucose concentrations were then modified as indicated. Fractions ( $2 \mathrm{ml})$ were collected at 2-min intervals and stored at $-20^{\circ} \mathrm{C}$ prior to assay for insulin. Rates of insulin release by islets isolated from HF (open symbols) and HF-DEX (closed symbols) rats (a). Rates of insulin release by islets isolated from HF-WY (open symbols) and HF-DEXWY (closed symbols) rats (b). Results are means \pm SEM for five HF, five HF-DEX, six HF-WY and five HF-DEX-WY rats. Statistically significant effects, see text
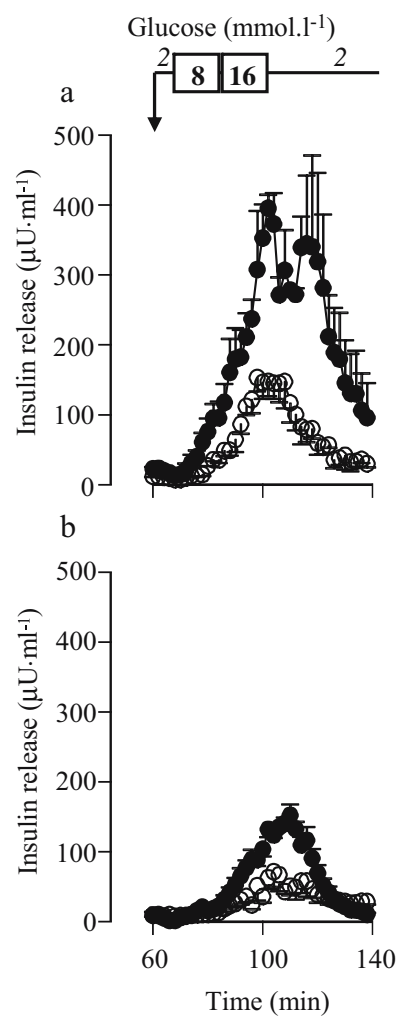

curves were calculated for discrete 16-min periods during which the perifusate glucose concentrations were rising: $\Delta 1$, during which the perifusate glucose concentration varied between 2 and $8 \mathrm{mmol}^{-1}$, and $\Delta 2$, during which the perifusate glucose concentration varied between 8 and $16 \mathrm{mmol} \mathrm{l}^{-1}$. Corresponding areas under the insulin curves over the equivalent 16-min periods of perifusion after switching to basal glucose are referred to as $\Delta 3$ and $\Delta 4$. Data are shown in Fig. 4. Reflecting glucocorticoidinduced increased glucose responsiveness at low extracellular glucose concentrations, $\Delta 1$ values for perifused islets from HF-DEX rats were significantly higher (8.3-fold; $p<0.001)$ than those of HF rats. In addition, $\Delta 2, \Delta 3$ and $\triangle 4$ values from HF-DEX islets exceeded corresponding values for the HF group (2.8-fold [ $p<0.001], 2.9$-fold $[p<0.001]$ and 5.3-fold [ $p<0.01]$, respectively), indicating increased efficacy of glucose stimulation of insulin secretion in vitro as a consequence of dexamethasone treatment, particularly at low compared with high stimulatory glucose levels. Antecedent PPAR $\alpha$ activation did not significantly affect $\Delta 1$ or $\Delta 4$ values for islets from HF rats, whereas it significantly lowered $\Delta 2$ and $\Delta 3$ values (by $68 \%[p<0.05]$ and $55 \%[p<0.05]$, respectively), indicating that PPAR $\alpha$ activation predominantly targets GSIS at high stimulatory glucose levels. In contrast, $\operatorname{PPAR} \alpha$ activation significantly lowered $\Delta 1, \Delta 2, \Delta 3$ and $\Delta 4$ values for GSIS in the HFDEX group (by 74\% [p<0.01], 69\% [p<0.001], 60\% $[p<0.001]$ and $86 \%[p<0.01]$, respectively). Thus, in summary, while the effect of PPAR $\alpha$ activation to suppress GSIS in HF rats is reiterated in isolated perifused islets, an effect of dexamethasone treatment to enhance GSIS is observed only in perifused islets. Furthermore, the effect of

a

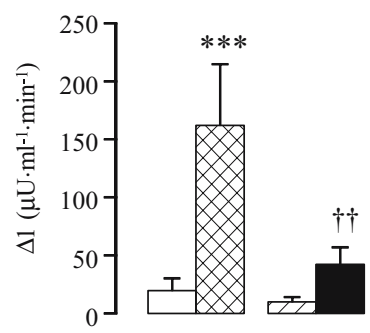

b
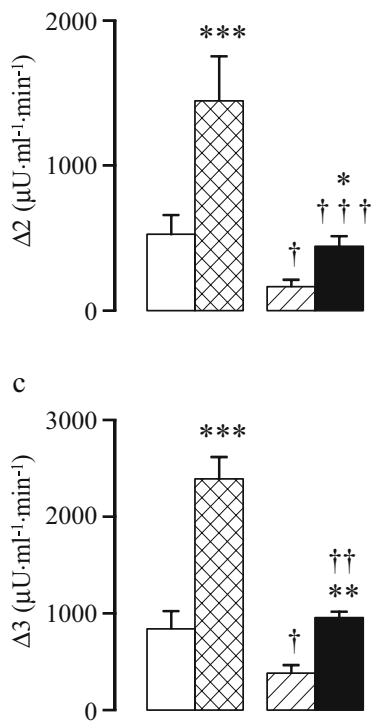

d

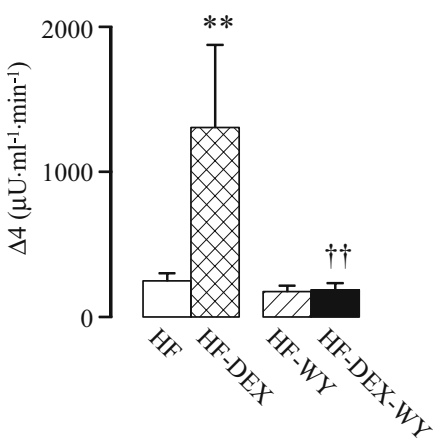

Fig. 4 Effects of dexamethasone and/or WY14643 treatment on individual areas under the insulin curves during perifusion of islets from high-fat-fed rats. To allow direct comparison of insulin secretory responses, areas under the insulin curves were calculated for discrete 16-min periods during which the perifusate glucose concentrations were rising: $\Delta 1$ : perifusate glucose concentration between 2 and $8 \mathrm{mmol} \mathrm{l}^{-1} ; \Delta 2$ : perifusate glucose concentration between 8 and $16 \mathrm{mmol} \mathrm{l}^{-1}$. After exposure to $16 \mathrm{mmol} \mathrm{l}^{-1}$ glucose, perifusate glucose was then lowered to basal levels by switching to basal $\left(2 \mathrm{mmol} \mathrm{l}^{-1}\right.$ glucose $)$ medium. Corresponding areas under the insulin curves over the equivalent 16-min periods of perifusion after switching to basal glucose are referred to as $\Delta 3$ and $\Delta 4$. a-d $\Delta 1$, $\Delta 2, \Delta 3$ and $\Delta 4$ values, respectively, for the HF (open bars), HFDEX (cross-hatched bars), HF-WY (hatched bars) and HF-DEXWY (closed bars) groups. Data are means \pm SEM for five HF rats, five HF-DEX rats, five HF-WY rats and five HF-DEX-WY rats. $* p<0.05, * * p<0.01$ and $* * * p<0.001$ for effects of dexamethasone treatment; ${ }^{\dagger} p<0.05,{ }^{\dagger \dagger} p<0.01$ and ${ }^{\dagger \dagger} p<0.001$ for effects of WY14643 treatment 
$\operatorname{PPAR} \alpha$ activation to suppress GSIS in HF rats dominates over the effect of dexamethasone to elevate GSIS when GSIS is examined ex vivo.

Dexamethasone treatment of high-fat-fed rats does not affect circulating plasma lipid concentrations, but elevates plasma leptin concentrations

To identify potential factors that might suppress GSIS in dexamethasone-treated high-fat-fed rats in vivo, we examined effects of dexamethasone treatment on circulating lipids (which can augment or impair GSIS, depending on the period of exposure) and on leptin, which in general suppresses GSIS. Dexamethasone treatment of high-fatfed rats did not modulate circulating fatty acid concentrations (HF, $0.48 \pm 0.08 \mathrm{mmol}^{-1}, n=9$; HF-DEX, 0.53 \pm $\left.0.19 \mathrm{mmol} \mathrm{l}^{-1}, n=6\right)$ or triacylglycerol concentrations (HF, $0.82 \pm 0.15 \mathrm{mmol} 1^{-1}, n=9$; HF-DEX, 0.57士 $\left.0.18 \mathrm{mmol} \mathrm{l}^{-1}, n=6\right)$. In contrast, dexamethasone treatment elicited a significant and dramatic 4.8 -fold increase in plasma leptin levels (HF, $5.8 \pm 1.7 \mathrm{ng} \mathrm{ml}^{-1}, n=9$; HFDEX, 28.1 $\left.\pm 3.6 \mathrm{ng} \mathrm{ml}^{-1}, n=6 ; p<0.001\right)$.

\section{Discussion}

Normally, in healthy human subjects, changes in insulin sensitivity are compensated by reciprocal changes in GSIS such that the product of insulin sensitivity and insulin secretion remains unchanged (reviewed in [25]). This is reiterated in Wistar rats fed a high level of saturated fats. Although very long-term (10 months) high-saturated-fat feeding of Wistar rats leads to severe insulin resistance, overt diabetes does not develop [26]. In the highsaturated-fat feeding protocol of Wistar rats used in the present study (female Wistar rats; moderate lipid content; 4 weeks of dietary manipulation), euglycaemic-hyperinsulinaemic clamp studies have demonstrated peripheral insulin resistance, but unimpaired hepatic insulin sensitivity [11], and enhanced insulin secretion that allows maintenance of glucose tolerance [15]. Glucocorticoids impair glucose homeostasis by opposing insulin's actions to suppress hepatic glucose production and stimulate peripheral glucose uptake. In the present study, we observed that dexamethasone treatment of rats fed a high level of saturated fats elicited glucose intolerance after an acute intravenous glucose challenge. This response was observed in conjunction with fasting hyperinsulinaemia, but a blunted initial response of insulin secretion to a rise in glycaemia. Overall, the GSIS in vivo in response to an acute glucose challenge ( $\Delta \mathrm{I}$ value) was not diminished, but neither was it enhanced sufficiently to prevent glucose intolerance. The finding that GSIS in perifused islets from dexamethasone-treated, high-fatfed rats exceeds that of high-fat-fed rats not treated with dexamethasone implies a degree of islet adaptation for the additional impairment in insulin action introduced by dexamethasone treatment. Our data imply that insulin resistance induced by high-fat feeding is exacerbated by glucocorticoid excess and, although our studies with perifused islets demonstrated that dexamethasone treatment exerts a persistent effect on the islet, which allows augmented GSIS ex vivo, additional factors must operate in the intact organism to oppose the glucocorticoid-induced enhancement of islet insulin secretion that is identified with perifused islets. At present, the identity of these factors remains to be established, but they presumably relate to interactions between increased dietary lipid supply and glucocorticoid excess, interactions which may interrupt the negative feedback loop between insulin sensitivity and secretion in vivo. Although we observed that dexamethasone treatment of high-fat-fed rats did not modulate circulating fatty acid or triacylglycerol concentrations, plasma leptin levels were dramatically increased. Since leptin is known to suppress GSIS [27] it may be involved in uncoupling insulin secretion from insulin action. As the disruption of feedback between insulin sensitivity and secretion in vivo in dexamethasone-treated, high-fatfed rats precipitates the development of glucose intolerance, it reproduces the transition from insulin resistance with islet compensation to type 2 diabetes.

In the present study, neither PPAR $\alpha$ activation alone nor dexamethasone treatment alone exerted any major influence on fasting glycaemia in high-fat-fed rats. However, marked fasting hyperglycaemia was observed in high-fatfed rats by the combination of dexamethasone treatment and PPAR $\alpha$ activation. Hepatic lipid oxidation is augmented by PPAR $\alpha$ activation, and this provides ATP and cofactors to sustain or enhance flux through the gluconeogenic pathway, the capacity of which is established to be increased in response to glucocorticoids. Like the action of the glucocorticoids, PPAR $\alpha$ activation is an integral component of normal starvation adaptation, as demonstrated from the development of fasting hypoglycaemia in PPAR $\alpha$-null mice [7]. Hence the hepatic adaptation to starvation, namely enhanced hepatic glucose production, may be reproduced by exposure to excess glucocorticoids in combination with PPAR $\alpha$ activation under conditions of high-fat feeding, even though dietary carbohydrate is available and energy intake is not compromised, with resultant fasting hyperglycaemia.

$\operatorname{PPAR} \alpha$ activation enhances insulin sensitivity in peripheral tissues of high-fat-fed rats [16]. This reduces the necessity for compensatory insulin hypersecretion to maintain glucose tolerance [15]. Thus, as shown in the present experiments, PPAR $\alpha$ activation in vivo by the administration of WY14643 did not affect glucose tolerance (as reflected by incremental blood glucose values integrated over the 30-min period after the injection of glucose $[\Delta \mathrm{G}]$ and rates of glucose disappearance $[k]$ values) in HF rats, despite lowered GSIS (which is observed both in vivo after a glucose bolus and ex vivo in islets perifused at high glucose concentrations). Since antecedent PPAR $\alpha$ activation in vivo results in a stable lowering of GSIS in perifused islets isolated from high-fat-fed rats, it is implied that increased GSIS in perifused islets from high-fat-fed rats reflects a stable islet adaptation enabling compensatory insu- 
lin secretion. The observation with ex-vivo perifused islets that antecedent PPAR $\alpha$ activation elicits partial reversal of the stable effect of dexamethasone treatment of high-fat-fed rats to augment GSIS is consistent with stable PPAR $\alpha$-induced modification of islet function that opposes augmentation of islet GSIS, which may be linked to improved peripheral insulin action in vivo as a consequence of PPAR $\alpha$ activation.

PPAR $\alpha$ activation slightly exaggerated the fasting hyperinsulinaemia elicited in high-fat-fed rats in response to dexamethasone treatment. More importantly, in contrast to the data obtained ex vivo using perifused islets, antecedent $\operatorname{PPAR} \alpha$ activation greatly augmented GSIS in dexamethasone-treated high-fat-fed rats in vivo, such that glucose tolerance was improved. Thus, within the context of highfat feeding, PPAR $\alpha$ activation in vivo restores the interorgan operation of the negative feedback loop between insulin action and secretion that is interrupted by dexamethasone treatment.

Acknowledgements This study was supported in part by a project grant from Diabetes UK (RD01/2249) to M.C. Sugden and M.J. Holness G.K. Greenwood is a recipient of a Diabetes UK studentship.

\section{References}

1. Barthel A, Schmoll D (2003) Novel concepts in insulin regulation of hepatic gluconeogenesis. Am J Physiol Endocrinol Metabol 285:E685-E692

2. Andrews RC, Walker BR (1999) Glucocorticoids and insulin resistance: old hormones, new targets. Clin Sci (Lond) 96:513523

3. Perry CG, Spiers A, Cleland SJ, Lowe GD, Petrie JR, Connell JM (2003) Glucocorticoids and insulin sensitivity: dissociation of insulin's metabolic and vascular actions. J Clin Endocrinol Metab 88:6008-6014

4. Ekstrand A, Saloranta C, Ahonen J, Gronhagen-Riska C, Groop LC (1992) Reversal of steroid-induced insulin resistance by a nicotinic-acid derivative in man. Metabolism 41:692-697

5. Escher P, Braissant O, Basu-Modak S, Michalik L, Wahli W, Desvergne B (2001) Rat PPARs: quantitative analysis in adult rat tissues and regulation in fasting and refeeding. Endocrinology 142:4195-4202

6. Minnich A, Tian N, Byan L, Bilder G (2001) A potent PPARalpha agonist stimulates mitochondrial fatty acid betaoxidation in liver and skeletal muscle. Am J Physiol Endocrinol Metabol 280:E270-E279

7. Kersten S, Seydoux J, Peters JM, Gonzalez FJ, Desvergne B, Wahli W (1999) Peroxisome proliferator-activated receptor alpha mediates the adaptive response to fasting. J Clin Invest 103:1489-1498

8. Lemberger T, Saladin R, Vazquez M et al (1996) Expression of the peroxisome proliferator-activated receptor alpha gene is stimulated by stress and follows a diurnal rhythm. J Biol Chem 271:1764-1769

9. Bernal-Mizrachi C, Weng S, Feng C et al (2003) Dexamethasone induction of hypertension and diabetes is PPAR-alpha dependent in LDL receptor-null mice. Nat Med 9:1069-1075

10. Storlien LH, James DE, Burleigh KM, Chisholm DJ, Kraegen EW (1986) Fat feeding causes widespread in vivo insulin resistance, decreased energy expenditure, and obesity in rats. Am J Physiol Endocrinol Metab 251:E576-E583
11. Holness MJ, Kraus A, Harris RA, Sugden MC (2000) Targeted upregulation of pyruvate dehydrogenase kinase (PDK)-4 in slow-twitch skeletal muscle underlies the stable modification of the regulatory characteristics of PDK induced by high-fat feeding. Diabetes 49:775-781

12. Holness MJ, Sugden MC (1999) Antecedent protein restriction exacerbates development of impaired insulin action after highfat feeding. Am J Physiol Endocrinol Metabol 276:E85-E93

13. Storlien LH, Kriketos AD, Jenkins AB et al (1997) Does dietary fat influence insulin action? Ann N Y Acad Sci 827: 287-301

14. Kraegen EW, Cooney GJ, Ye JM, Thompson AL, Furler SM (2001) The role of lipids in the pathogenesis of muscle insulin resistance and beta cell failure in type II diabetes and obesity. Exp Clin Endocrinol Diabetes 109(Suppl 2):S189-S201

15. Holness MJ, Smith ND, Greenwood GK, Sugden MC (2003) Acute $(24 \mathrm{~h})$ activation of peroxisome-proliferator-activated receptor (PPAR) $\propto$ reverses high-fat feeding induced insulin hypersecretion in vivo and in perifused pancreatic islets. J Endocrinol 177:197-205

16. Ye JM, Doyle PJ, Iglesias MA, Watson DG, Cooney GJ, Kraegen EW (2001) Peroxisome proliferator-activated receptor (PPAR)-alpha activation lowers muscle lipids and improves insulin sensitivity in high fat-fed rats: comparison with PPARgamma activation. Diabetes 50:411-417

17. Roduit R, Morin J, Masse F et al (2000) Glucose downregulates the expression of the peroxisome proliferator-activated receptor-alpha gene in the pancreatic beta-cell. J Biol Chem 275:35799-35806

18. Zhou YT, Shimabukuro M, Wang MY et al (1998) Role of peroxisome proliferator-activated receptor alpha in disease of pancreatic beta cells. Proc Natl Acad Sci U S A 95:8898-8903

19. Sugden MC, Holness MJ (2004) Potential role of peroxisome proliferator-activated receptor-alpha in the modulation of glucose-stimulated insulin secretion. Diabetes 53(Suppl 1): S71-S81

20. Henquin JC (2004) Pathways in beta-cell stimulus-secretion coupling as targets for therapeutic insulin secretagogues. Diabetes 53(Suppl 3):S48-S58

21. Holness MJ, Sugden MC (2001) Dexamethasone during late gestation exacerbates peripheral insulin resistance and selectively targets glucose-sensitive functions in beta cell and liver. Endocrinology 142:3742-3748

22. Brun S, Carmona MC, Mampel T et al (1999) Activators of peroxisome proliferator-activated receptor-alpha induce the expression of the uncoupling protein-3 gene in skeletal muscle: a potential mechanism for the lipid intake-dependent activation of uncoupling protein-3 gene expression at birth. Diabetes 48:1217-1222

23. Holness MJ (1996) Impact of early growth retardation on glucoregulatory control and insulin action in mature rats. Am J Physiol Endocrinol Metabol 270:E946-E954

24. Sugden MC, Greenwood GK, Smith ND, Holness MJ (2003) Peroxisome proliferator-activated receptor-alpha activation during pregnancy attenuates glucose-stimulated insulin hypersecretion in vivo by increasing insulin sensitivity, without impairing pregnancy-induced increases in beta-cell glucose sensing and responsiveness. Endocrinology 144:146-153

25. Bergman RN, Finegood DT, Kahn SE (2002) The evolution of beta-cell dysfunction and insulin resistance in type 2 diabetes. Eur J Clin Invest 32 (Suppl 3):35-45

26. Chalkley SM, Hettiarachchi M, Chisholm DJ, Kraegen EW (2002) Long-term high-fat feeding leads to severe insulin resistance but not diabetes in Wistar rats. Am J Physiol Endocrinol Metabol 282:E1231-E1238

27. Kieffer TJ, Habener JF (2000) The adipoinsular axis: effects of leptin on pancreatic beta-cells. Am J Physiol Endocrinol Metabol 278:E1-E14 